\title{
Cooperative Transportation Planning and Cost Allocation
}

\author{
Joen Dahlberg
}


Cooperative Transportation Planning and Cost Allocation

Joen Dahlberg

LIU-TEK-LIC 0280-7971

ISBN 978-91-7685-969-8

ISSN $0280-7971$

Linköping University

Department of Science and Technology

SE-601 74 Norrköping

Printed by LiU Tryck, Linköping, Sweden 2015 


\section{Abstract}

A freight forwarder may consolidate its goods transportations in order to achieve a more efficient operation. When goods transportations are consolidated, they may reduce operational costs, e.g. labor and fuel. This can be further improved if a number of freight forwarders cooperate and consolidate their collective goods transportations, i.e. it is a cooperation between competitors, a coopetition. In order to maintain the cooperation, a suitable business model, in which fair cost allocations plays an important role is essential. The potential by cooperating is not exclusive to freight forwarders, but in fact, any type of goods transportation planning may benefit from cooperation. In this thesis, cooperative game theory is used as an academic tool to study cooperation between stakeholders in different transportation planning applications. Cooperative game theory defines a number of criteria for fair cost allocations.

In Paper 1, the role of the municipality as an enabler of a cooperation between fictitious freight forwarders in an urban area, is studied. In this case, the municipality acts as a stakeholder with unusual characteristics. It is shown that a stable cooperation can be achieved if the municipality is willing to carry some of the cost. This cost is specified and discussed in Paper 1. The results of Paper 2 contribute to game theory by introducing a further development of a cost allocation method. Some small numerical examples are presented in order to illustrate the resulting changes. In Paper 3, the process of establishing a cooperation is studied, where the stakeholders, in this case forest companies, join the cooperation sequentially. Who will join and in what order, is not predetermined. It is shown that a stable cooperation can be achieved despite the uncertainty. This is done by using the cost allocation methods presented. 



\section{Acknowledgments}

The research behind this thesis was carried out at both the Swedish National Road and Transport research Institute (VTI) and in the division of Communication and Transport Systems (KTS), at the Department of Science and Technology (ITN) of Linköping University (LiU). It was financed by Swedish Energy Agency. I am very grateful for the useful guidance, collaboration and discussions with my supervisors at LiU, Maud Göthe-Lundgren and Stefan Engevall; thank you(!) for a lot of fun, interesting and productive discussions. I would also like to thank my supervisor at VTI, Jenny Karlsson, for giving feedback on Paper 1-3 and this thesis. A thank you to the rest of my colleagues at both KTS and VTI is also in order.

Norrköping, September 2015

Joen Dahlberg 

'När ingen något vet, hörs heller intet knyst och man ej forskar alls, om blott man forskar tyst'

'If no one nothing knows, nothing will be said and no research is done, if results can not be read'

- Joen Dahlberg, a free translation and modification from Molière's play 'Tartuffe'. 



\section{Contents}

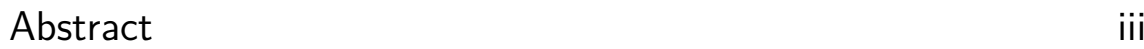

Acknowledgments $\quad v$

1 Introduction 1

1.1 Background 1

1.2 Motivation 2

1.3 Contribution 4

1.4 Outline 5

2 Cooperation in Transportation Planning 7

2.1 Consolidation 8

3 Cooperative Game Theory 11

$\begin{array}{ll}3.1 \text { Solution concepts } & 13\end{array}$

$\begin{array}{lll}3.1 .1 & \text { Solution properties } & 13\end{array}$

$\begin{array}{ll}\text { 3.1.2 Basic solution concepts } & 15\end{array}$

3.1.3 Solution concepts used in Papers 1-3 16 
3.1.4 Other solution concepts 21

3.2 Some comments on game theory 22

$\begin{array}{lll}3.3 & \text { Applications } & 23\end{array}$

4 Summary of Papers $\quad 27$

$\begin{array}{lll}4.1 & \text { Case studies } & 27\end{array}$

$\begin{array}{ll}\text { 4.1.1 City logistics } & 28\end{array}$

$\begin{array}{lll}4.1 .2 & \text { Forest industry } & 30\end{array}$

4.2 Results and summary of Paper 1-3 31

4.2.1 Summary of Paper $1 \quad 31$

4.2.2 Summary of Paper $2 \quad 32$

4.2.3 Summary of Paper $3 \quad 32$

5 Conclusions and Future Research 35

5.1 Conclusions and potential continuation of Paper 1-3 35

$\begin{array}{lll}5.2 & \text { Future research and discussion } & 37\end{array}$

$\begin{array}{ll}\text { Bibliography } & 39\end{array}$

$\begin{array}{ll}\text { Abbreviations } & 47\end{array}$

$\begin{array}{ll}\text { Paper } 1 & 49\end{array}$

Paper $2 \quad 85$

$\begin{array}{ll}\text { Paper } 3 & 97\end{array}$ 


\section{Chapter 1}

\section{Introduction}

\subsection{Background}

Historically, transportation has always been essential for trade, economic growth and prosperity. Whether it is a farmer selling vegetables at the local market or a merchant travelling the world trading spices and jewellery, they all need transportation. Needless to say, much has changed since distant past. But the need for transportation remains, this situation is unlikely to change in the near future.

Tavasszy et al. (2003) claim that there has been a steady, on average, growth of international trade and international transport. Similar claims has been reported about freight transports in Sweden by Trafikanalys (Östlund and Myhr, 2015).

According to Stadtler and Kilger (2005, p.229), freight transports can be reduced. 'A particularly effective consolidation of small shipments is achieved by a logistics service provider (LSP), who can combine the transports from many senders.'

A Logistics Service Provider (LSP) is a company that sells logistics solutions and services. A large number of the world's freight transports are made by LSPs. The leading LSP in the world is DHL with an annual gross revenue of US \$32B, followed by Kuehne + Nagel, Schenker 
and Nippon Express with annual gross revenues of US\$18B-US\$23B (Armstrong \& Associates, Inc. ${ }^{1}$ )

It is arguably more efficient to extend the consolidation as a cooperation between LSPs and/or other types of transportation companies. However, in order to maintain a cooperation, it is crucial to have a suitable business model, in which making fair cost allocations plays an important role, e.g. (Taniguchi, 2014). If there was no fair cost allocation, a subset of the stakeholders in the cooperation might have economic incitement to abandon the cooperation, e.g. the allocated cost to the subset might be larger than the cost would be if the subset excluded the other stakeholders.

In this thesis, cooperative game theory, a subgenre of game theory, is used as an academic tool to study cooperation between stakeholders in different transportation planning applications. Cooperative game theory defines a number of criteria for fair cost allocations. Game theory is the study of strategic decision making and relates to economic mathematics. One of the earlier references is the work of von Neumann and Morgenstern (1944).

\subsection{Motivation}

Cooperation enables further improvements in logistic operations and supply chains. The fundamental idea is simple: the more quantity you have, the more synergy you have, and thus, it is possible to be more efficient. Cruijssen et al. (2005, p.2) formulate this as '... the LSP's larger economies of scale that enable him to perform transportation and warehousing more efficiently than his customers.' But there are downsides as well; e.g. when the number of stakeholders in the cooperation increases, the required coordination increases. At the same time, the communication between the stakeholders becomes increasingly difficult, which makes good coordination more difficult to accomplish. Guajardo and Rönnqvist (2015) study the issue of maintaining large cooperations in logistic activities and suggest a model to form some smaller stable cooperations rather than one large cooperation. Stable in this context means that no subset of stakeholders

\footnotetext{
${ }^{1}$ http//www.3plogistics.com/Top_50_Global_3PLs.htm (June 2015)
} 
in the cooperation is allocated a greater collective cost than the cost if they acted without the others, see Section 3.1.

Cooperation between competitors is sometimes called coopetition or horizontal cooperation. Bengtsson and Kock (2000) study the importance of coopetition from both perspectives; competition and cooperation. They argue that these two perspectives are not mutually exclusive.

Cooperation in goods transportation can lead to a reduction of emissions and congestion, e.g. (Teo et al., 2012; Wangapisit et al., 2014; Eriksson et al., 2006). Not only will the environmental and social impacts be reduced, but the operational costs, e.g. fuel and labor, may be reduced as well. It is then crucial to make a fair allocation of costs in order to maintain the cooperation, e.g. (Browne et al., 2007; Cherrett et al., 2009). The decision process for allocating cost is referred to as the cost allocation problem.

When a cooperation is considered and the operations are optimized on a system level, they may be non-optimal for some stakeholders. Cooperative game theory can then be used as a tool to encourage system optimal solutions by providing cost allocations which are beneficial to all stakeholders.

Researchers have studied the cost allocation problem using cooperative game theory in the context of transportation planning. GötheLundgren et al. (1996) and Engevall et al. (2004) study the Vehicle Routing Game, where the cost of a Vehicle Routing Problem (VRP) ${ }^{2}$. is allocated to the customers that are visited in the VRP

Özener and Ergun (2008) study the allocation of costs in a transportation network. Shippers cooperate, and the cost of covering all demand in the network is optimized. The cost is allocated amongst the shippers.

Yang and Odani (2007) study a cost allocation problem with a City Distribution Center (CDC). In their paper they simultaneously allocate fixed costs (such as construction costs for the CDC, investment costs for the vehicles etc.) and operational costs amongst the truckfocused logistics companies cooperating.

\footnotetext{
${ }^{2}$ More details on VRPs can be found in the work of Toth and Vigo (2002).
} 
Agarwal and Ergun (2010) study the cost allocation to carriers in liner shipping. Their work is motivated by the commonly observed formation of carrier alliances in order to make more efficient use of the heavy investments generally needed in the industry.

Vanovermeire and Sörensen (2014) argue that companies with large flexibilities should be rewarded. However, in the case of two-partner coalitions, flexibility is not usually rewarded when cooperative game theory is used. Thus, the authors propose an alternative approach to allocate the costs.

Cruijssen et al. (2005) study the case where a LSP proactively invites shippers, with a strong synergy potential, to cooperate by means of a cost savings offer.

The stakeholders in the cost allocation problems are often treated equally. However, it is possible that some of the stakeholders have other, non-monetary reasons, for joining the cooperation, and thus should not necessarily be treated like the other stakeholders. This is exemplified in Paper 1 and Paper 3 of this thesis, and the consequences are studied.

\subsection{Contribution}

As pointed out in Section 1.2, in the literature on cooperative game theory, in the context of transportation planning, the stakeholders are often treated equally. There is a lack of studies on cooperations where at least one stakeholder, in some way, differs from the other stakeholders. Such cooperations are studied in Paper 1 and Paper 3, using two different cases. Both cases include an initiator, or enabler, of the cooperation, that is to say a dominant player.

It is also pointed out that fair cost allocations are a necessity for sustainable cooperations, e.g. (Taniguchi, 2014). In Paper 1 and Paper 3, it is shown that stable cooperations can be achieved using concepts from cooperative game theory and how to achieve stable cooperations is also elaborated.

In Paper 2, an issue concerning one of the concepts from cooperative 
game theory is identified and discussed. It is shown that the cost allocation according to the Equal Profit Method (EPM), see Section 3.1 .3 , is not always unique. Paper 2 contributes to cooperative game theory by introducing an extended version of the EPM which ensures a unique cost allocation.

Parts of the results in Paper 1 and Paper 3 have been presented by the author at the following conferences.

Paper 1

- Nationella konferensen i transportforskning (The Swedish national conference in transport research), Gothenburg, Sweden, October 2013.

- Svenska operationsanalyskonferensen (The Swedish conference in operations research), Gothenburg, Sweden, October 2013.

Paper 3

- Nationella konferensen i transportforskning (The Swedish national conference in transport research), Norrköping, Sweden, October 2014.

- $4^{\text {th }}$ Symposium of the European Association for Research in Transportation, Copenhagen, Denmark, September 2015.

\subsection{Outline}

In Chapter 2, a short overview of transportation planning applications, where cooperation may occur, is given. This is the common theme of Paper 1 and Paper 3.

In Chapter 3, the scientific tool used in Paper 1-3, i.e. cooperative game theory, is thoroughly explained. The chapter is mainly theoretical, but ends with examples of different applications where cooperative game theory has been used.

In Section 4.1, two case studies are described. The first case study is a fictitious City Logistics (CL) setting which is considered in Paper 1. 
The second case study is a real case from the Swedish forest industry and is considered in Paper 3. Paper 1-3 are summarized in Section 4.2 .

Chapter 5 consists of some conclusions and possible future studies. Paper 1-3 are attached after a list of abbreviations. 


\section{Chapter 2}

\section{Cooperation in \\ Transportation Planning}

The common theme of Paper 1 and Paper 3, and to some minor extent in Paper 2, is cooperation in transportation planning. In this chapter, a brief overview of transportation planning applications is presented. There are examples, related to transportation planning, where cooperation may occur, some of which are presented below.

Cooperation may occur between a number of freight forwarders with different types of goods, but which are bound for the same customers, e.g. CL, see Section 4.1.1. One example of such a system is established in Lucca, an Italian city with a historical city center from the $16^{\text {th }}$ century. In order to preserve the quality of the environment and the historical area, as well as tourist assets, local authorities have taken a number of measures (Ambrosino et al., 2007), e.g. introduced regulations and mobility schemes as well as constructing a consolidation center just outside the city center.

In Sweden, some municipalities have started to coordinate their daily goods distribution to schools and hospitals etc. (Moen, 2014). Cooperation can also be used when handling waste disposal. In a UK context, Cherrett et al. (2009) report of such a system in Winchester, where local shops invest in a coordinated waste disposal system. 
Cooperation may also occur when there are transportation needs in two directions of the same system. This is called backhauling. Ropke and Pisinger (2006) present a heuristic method to solve VRPs with backhauls. A typical example of such a transportation problem which they point out, is soda distribution. The sodas are transported in crates which are left at the customer's, while crates filled with empty bottles are sent back. Bailey et al. (2011) develop optimization models in the context of backhaul and cooperation between freight carriers.

Stakeholders who share a common type of resource can reduce transportation costs due to synergy effects when the resource is bartered. They cooperate in terms of supply sharing. Forsberg et al. (2005) provide examples of the bartering of wood to reduce transportation costs in the forest industry.

Vendor Managed Inventory (VMI) is an example where cooperation occurs between different types of stakeholders with similar interest. In a VMI setting, a supplier is responsible for managing the inventory of their customers. In exchange for this additional work, the supplier receives useful information which results in better plans. $\mathrm{Li}$ et al. (2015) use cooperative game theory in order to achieve a stable VMI cooperation.

\subsection{Consolidation}

In order to reduce the number of vehicles needed in transportation planning, freight can be consolidated and sent in larger bulks. In this context, consolidation is referred to as the merging of smaller transport volumes to one common transport. This is done in e.g. multimodal transports, i.e. transport using more than one transportation mode, e.g. by truck and container ship. The transitions between the modes require suitable infrastructure and locations that enable the modal change. Sometimes there are no modal changes, but instead of using two half full vehicles, one full vehicle might be more efficient. While, in some circumstances, it is efficient to consolidate, each transition includes additional costs. Thus, consolidation is not always the best solution. 
Consolidation centers are facilities dedicated to consolidating freight. Trucks are used for the transportations. But sometimes, especially in CL, see Section 4.1.1, other vehicles, such as electric cars and bicycles, may be used. The purpose of a consolidation center is mainly to consolidate and redistribute the freight. Thus, it has no, or just a small, internal inventory.

Van Duin et al. (2013) study the potential for an electric vehicles fleet for a consolidation center in Amsterdam by solving a number of VRPs with constraints related to the battery capacities. The costs for using different fleet compositions are compared.

Crainic et al. (2009) present a model for solving a day-before problem, a problem type where the demands for the next day is known and the distribution is to be planned, in a CL context using a number of consolidation centers. The new problem is denoted as the two-echelon, synchronized, scheduled, multidepot, multiple-tour, heterogeneous vehicle routing problem with time windows (2SS-MDMTVRPTW).

When deciding upon the strategic placement of consolidation centers, the localization problem can be solved by optimization. The localization problem can be modeled with different layers or echelons of supply chains, typically used when one or a few major consolidation centers will be located as well as smaller local delivery stations. The major consolidation centers, constitute one echelon and the small delivery stations constitute another echelon. Tragantalerngsak et al. (2000) provide a mathematical model to solve the two-echelon facility location problem. 



\section{Chapter 3}

\section{Cooperative Game Theory}

This chapter provides a general overview of cooperative game theory, which is used as a tool in Paper 1 and Paper 3. In Paper 2, a solution concept is further developed.

A game consists of a set of players, a set of choices the players can make and lastly some consequences for each combination of choices. Each player does not necessarily have the same choices as another player. An example of a game is the prisoner's dilemma (Tucker, 1950; Tucker, 1983). Two people, A and B, are arrested; both are suspected of having participated in a crime. Each of them can choose either to stay silent or to testify that the other person committed the crime. The punishments are dependent upon their choices, see Table 3.1 .

\begin{tabular}{|l|l|l|}
\cline { 2 - 3 } \multicolumn{1}{c|}{} & B stays silent & B testifies \\
\hline A stays silent & A: 1 year in prison & A: 3 years in prison \\
& B: 1 year in prison & B: goes free \\
\hline A testifies & A: goes free & A: 2 years in prison \\
& B: 3 years in prison & B: 2 years in prison \\
\hline
\end{tabular}

Table 3.1: Outcomes of the prisoner's dilemma

Cooperative games is a sub-genre of games that has been particularly interesting for the problems considered in Paper 1-3. A cooperative 
game $(N, f)$ consists of a set of numbered players $N=\{1,2, \ldots, n\}$ and a function $f$ that is defined $\forall S \subseteq N$, mapped on $\mathbb{R}$. It is common to define $f(\emptyset)=0$ and for simplicity, write $f(i)$ instead of $f(\{i\})$. The function $f$ is called the characteristic function. All subsets of $N$ are called coalitions and $N$ itself is called the grand coalition. The values of the characteristic function correspond to how costly or profitable the coalitions are. A solution to a cooperative game is a vector $y=$ $\left(y_{1}, y_{2}, \ldots, y_{n}\right) \in \mathbb{R}^{n}$. A solution represents how much each player will pay/receive. Let $y(S):=\sum_{i \in S} y_{i}$, if $y(N)=f(N)$, then the solution is called an outcome.

Cooperative games can be divided into two categories; cooperative cost games and cooperative profit games. We may distinguish the two categories by changing the notation of the characteristic function, i.e. $(N, c)$ denotes a cooperative cost game and $(N, v)$ a cooperative profit game. A cost allocation is a solution to $(N, c)$ and a payoff is a solution to $(N, v)$. Any cooperative cost game can easily be rewritten as a cooperative profit game. The other way around requires that the individual costs, $c(i)$ are known. The relationship is $v(S)=$ $\sum_{i \in S} c(i)-c(S)$. A cooperative game is proper if $c(S)+c(T) \geqslant c(S \cup T)$ or $v(S)+v(T) \leqslant v(S \cup T), \forall S, T \subseteq N, S \cap T=\emptyset$.

If a player wants to ensure cooperation in a cooperative game, side payments can be used. A player may pay the other players some kind of compensation, in order to ensure a cooperation. Let $s_{i j}$ denote the side payment from player $i$ to player $j$. Then for some player, $k$, with an allocated cost of $y_{k}$, will have a final cost $y_{k}^{f}=y_{k}+\sum_{j \in N} s_{k j}-\sum_{i \in N} s_{i k}$. The usage of side payments is treated, from an application point of view, e.g. in Paper 1 and also by Agarwal et al. (2010). In the case of the prisoner's dilemma, such payments can not be used. The currency or utility (in this case years) is not transferable, whereas in games such as those described in Paper 1, both resources and money are transferable. 


\subsection{Solution concepts}

A solution concept yields a set, $Y$, of solution candidates to a cooperative game. We may exclude all cooperative games such that $Y=\emptyset$ and say that the solution concept is not defined for those cooperative games. Either $Y$ has one, some or infinitely many elements, all depending on the cooperative game and the solution concept. When cooperative cost games are considered, another expression for 'solution concept' is cost allocation method.

There are some properties, or fairness criteria, that a solution concept may fulfill. When a solution concept is considered as a part of a business model, three properties are arguably more relevant than the others. These are efficiency, individual rationality and group rationality. If these three properties are fulfilled, then there is no monetary (short term) incitement to not cooperate.

\subsubsection{Solution properties}

Let $\Phi$ denote any specific solution concept. For a given cooperative game $(N, f), \Phi$ yields a set of solution candidates denoted $Y_{(N, f)}^{\Phi}$.

$\Phi$ fulfills efficiency if all $y \in Y_{(N, f)}^{\Phi}$ are outcomes. That is, the value of the grand coalition should be allocated amongst the players, $y(N)=$ $f(N)$.

$\Phi$ fulfills individual rationality if $y_{i} \leqslant c(i), \forall y \in Y_{(N, c)}^{\Phi}, \forall i \in N$ and $y_{i} \geqslant v(i), \forall y \in Y_{(N, v)}^{\Phi}, \forall i \in N$. That is, no player should pay more/get less than the player would pay/get if the player acted alone.

$\Phi$ fulfills group rationality if $y(S) \leqslant c(S), \forall y \in Y_{(N, c)}^{\Phi}, \forall S \subseteq N$ and $y(S) \geqslant v(S), \forall y \in Y_{(N, v)}^{\Phi}, \forall S \subseteq N$. If a solution concept fulfills group rationality it also, by definition, fulfills individual rationality.

Let $m_{(i, S)}^{f}:=f(S)-f(S \backslash\{i\}), m_{(i, S)}^{c}$ is called marginal cost $\left(m_{(i, S)}^{v}\right.$ is called marginal profit) of a player, $i$, to a coalition, $S$. Let $m_{i}^{f}:=$ $m_{(i, N)}^{f}, m_{i}^{c}$ is called the grand coalition marginal cost $\left(m_{i}^{v}\right.$ is called the grand coalition marginal profit) of player $i$. 
$\Phi$ fulfills incremental cost test if $\sum_{i \in S} y_{i} \geqslant c(N)-c(N \backslash S), \forall y \in Y_{(N, c)}^{\Phi}$, $\forall S \subseteq N$, where the difference $c(N)-c(N \backslash S)$ is called incremental cost. In a similar fashion, incremental profit and incremental profit test can be defined.

A player $i$ is called a dummy player if $f(i)=m_{(i, S)}^{f} \forall S \subseteq N$ such that $i \in S$. Let $N_{\text {dummy }}:=\{i \in N \mid i$ is a dummy player $\}$.

$\Phi$ fulfills dummy player property if $y_{i}=f(i), \forall y \in Y_{(N, f)}^{\Phi}, \forall i \in$ $N_{\text {dummy }}$. That is, if a player does not contribute to any coalition, the player should not receive any reduced cost or increased profit.

Let $\oplus$ denote the Minkowski addition ${ }^{1}$.

$\Phi$ fulfills additivity if $Y_{\left(N, f_{1}\right)}^{\Phi} \oplus Y_{\left(N, f_{2}\right)}^{\Phi}=Y_{\left(N, f_{1}+f_{2}\right)}^{\Phi}$, for any two characteristic functions defined for all $S \subseteq N$. In an operational application, there might be incitements to split the characteristic function into components, e.g. on a daily, weekly or yearly basis. A solution concept that fulfills additivity will yield the same end results, e.g. the solution to the cooperative game based on a yearly basis is equal to the sum (for all days over the year) of the solutions to the cooperative games based on a daily basis.

$\Phi$ fulfills anonymity if the following implication holds; $f(S \cup\{i\})=$ $f(S \cup\{j\}) \forall S \subset N$ such that $i, j \notin S \longrightarrow y_{i}=y_{j}, \forall y \in Y_{(N, f)}^{\Phi}$. That is, if two players who contribute equally to every coalition, then they should pay/get the same value.

$\Phi$ fulfills kick-back property if $y_{i} \geqslant 0, \forall y \in Y_{(N, f)}^{\Phi}$. That is, no player should pay/get negative value.

Two games, $(N, f)$ and $\left(N, f^{\prime}\right)$, are strategically equivalent if $f(S)=$ $\alpha f^{\prime}(S)+\sum_{i \in S} \delta_{i}, \forall S \subseteq N$, where $\alpha, \delta_{i} \in \mathbb{R}$ and $\alpha \geqslant 0$.

$\Phi$ fulfills covariance if for any two strategically equivalent games, the solutions satisfy $y_{i}=\alpha y_{i}^{\prime}+\delta_{i}, \forall y \in Y_{(N, f)}^{\Phi}, \forall y^{\prime} \in Y_{\left(N, f^{\prime}\right)}^{\Phi}, \forall i \in N$.

$\Phi$ fulfills uniqueness if $\left|Y_{(N, f)}^{\Phi}\right|=1$. That is, the solution is unique.

\footnotetext{
${ }^{1}$ Let $B$ and $C$ be two subsets of $\mathbb{R}^{n}, B \oplus C=\{b+c \mid b \in B, c \in C\}$.
} 


\subsubsection{Basic solution concepts}

Some solution concepts from the literature are presented below. For simplicity, only cooperative cost games are considered. The solution concepts are sorted into three categories; the first category comprises solution concepts that are related to the solution concepts used in Paper 1-3, the second category comprises the solution concepts used and introduced in Paper 1-3 and the last category comprises other common solution concepts from the literature which are not used in, or related to, Paper 1-3.

\section{The core}

The core was introduce by Gillies (1959) and is defined as all outcomes that satisfy group rationality. Thus, by definition, the core satisfies all three properties; efficiency, individual rationality and group rationality. Mathematically speaking, the core is defined as:

$$
\begin{aligned}
& y(S) \leqslant c(S), \quad \forall S \subset N, \\
& y(N)=c(N) .
\end{aligned}
$$

The set, $Y$, of solution candidates yielded by the core is often referred to as the core, like the solution concept itself. If a solution satisfies the constraints in 3.1 we say that the solution is stable or equivalent, the solution is in the core. Usually the core is either the empty set (empty core), or it is infinite, which from a decision making point of view is problematic. Due to this, in practical applications where the players are net gain (profit-cost) driven stakeholders, the core is rarely used as a solution concept in itself. But since it fulfills efficiency and both rationalities, it is common to use the core in conjunction with some additional method that reduces the set of solution candidates, e.g. the EPM which is used in Paper 1-3. In order to prevent an empty core, two extensions are presented by Shapley and Shubik (1963; 1966), the $\varepsilon$-core and the weak $\varepsilon$-core.

The $\varepsilon$-core

The $\varepsilon$-core is a relaxation of the core. The inequality constraints are relaxed by adding $\varepsilon \geqslant 0$ to the right hand side for each inequality 
constraint:

$$
\begin{aligned}
& y(S) \leqslant c(S)+\varepsilon, \quad \forall S \subset N, \\
& y(N)=c(N) .
\end{aligned}
$$

The $\varepsilon$-core can guarantee a non-empty core. This is done by choosing a sufficiently large value of $\varepsilon$.

The weak $\varepsilon$-core

The weak $\varepsilon$-core is similar to the $\varepsilon$-core, only the relaxation term is defined differently $(|S| \cdot \varepsilon$ compared to $\varepsilon)$.

$$
\begin{aligned}
& y(S) \leqslant c(S)+|S| \cdot \varepsilon, \quad \forall S \subset N, \\
& y(N)=c(N) .
\end{aligned}
$$

\subsubsection{Solution concepts used in Papers 1-3}

The v-core

An alternative extension of the core is the v-core, which is used in Paper 1 . The right hand side of the equality constraint is subtracted with $v \geqslant 0$ and the inequalities are not relaxed.

$$
\begin{aligned}
& y(S) \leqslant c(S), \quad \forall S \subset N, \\
& y(N)=c(N)-v .
\end{aligned}
$$

The three extensions of the core are similar, in the sense that they all prevent an empty core. However, they work slightly different. The $\varepsilon$-core relaxes each inequality constraint equally. From an application point of view, this means that all coalitions are treated equally. The relaxation can be seen as an acceptance from the coalitions. For a given solution $y$ and coalition $S \subseteq N$, the excess value $e(S, y):=$ $c(S)-y(S)$ can be seen as a measure of satisfaction. Some coalitions may have an excess value of $-\varepsilon$, which means they receive a higher collective allocated cost than if they acted without the others, by an amount of $\varepsilon$. If the weak $\varepsilon$-core is used instead, it is argued that 
larger coalitions should accept larger negative excess since they are more players who share the additional cost. This is why the relaxation term is scaled with the number of players in the coalition. The v-core does not relax any inequality constraint, instead the grand coalition cost, which is to be allocated amongst the players, is reduced by a value $v$. Then, the cost $v$ must be allocated separately in order to fullfil efficiency. The $\mathrm{v}$-core does not have a predefined way of allocating this value. In Paper 1 , the value of $\mathrm{v}$ is allocated to one specific player, although it could have been allocated in other ways.

\section{Equal Profit Method}

The Equal Profit Method (EPM) was originally presented by Frisk et al. (2010). The aim of the EPM is to yield a solution in the core such that the difference in pairwise relative costs, defined as $\frac{y_{i}}{c(i)}-\frac{y_{j}}{c(j)}$, is as small as possible. The fraction is a ratio between the allocated cost and the individual cost. If the differences in relative costs are zero, then each player receives an allocated cost equally proportional to their respective individual cost. The EPM is defined as an optimization problem

$$
\begin{array}{lr}
\min f, & \\
\frac{y_{i}}{c(i)}-\frac{y_{j}}{c(j)} \leqslant f, & \forall(i, j) \in N \times N, \\
y(S) \leqslant c(S), & \forall S \subset N, \\
y(N)=c(N) . &
\end{array}
$$

This is an example of a solution concept that uses the core in conjunction with some additional method, in this case minimizing the difference in relative costs. Even though the EPM may exclude a large portion of solution candidates, it does not necessarily yield a unique solution. In Paper 2, two examples are given, neither of which has a unique solution according to the EPM.

\section{Lexicographic Equal Profit Method}

In Paper 2, an extension of the EPM is developed, the Lexicographic EPM (EPML), which fulfills uniqueness and the necessity of the ex- 
tension is discussed. Lexicography is used in the EPML and is described below.

Let $\hat{x}=\left[\hat{x}_{1}, \hat{x}_{2}, \ldots, \hat{x}_{k}\right]$ and $\hat{z}$ be two lists of same size. If $\exists q \in \mathbb{N}$ such that $\hat{x}_{i}=\hat{z}_{i}, \forall i<q$ and $\hat{x}_{i}>\hat{z}_{i}, i=q$, then $\hat{x}$ is said to be lexicographically greater than $\hat{z}$ and the notation is $\hat{x}>_{L} \hat{z}$.

Let $s_{y}$ be the descending list of the values for the differences in relative savings $\frac{y_{i}}{c(i)}-\frac{y_{j}}{c(j)}$ for a given solution, $y$. Then the EPML yields the solution to 3.5 with the lexicographically smallest $s_{y}$.

To put it simply, if the EPM yields a non-unique solution, some players' allocated cost are not unique. The differences in relative savings between these players can be minimized further.

\section{$\Delta$-Equal Profit Method}

Another issue with the EPM occurs when any $c(i) \leqslant 0$. If $c(i)=0$ we have a division by zero, and if any $c(i)<0$ the fraction will increase when $y_{i}$ decreases; the opposite to the case when $c(i)>0$. The issue of $c(i)=0$ is addressed in Paper 1. It is suggested to calculate a lower bound, $l_{i}$ on the allocated cost for each player with $c(i)=0$ with respect to the core constraints and define relative savings as $\frac{y_{i}-l_{i}}{c(i)-l_{i}}$ for those players. However, it may be argued that each player should be treated in the same way. Thus, a new solution concept, the Delta-EPM $(\operatorname{EPM} \Delta)$, is presented, where all the fractions are defined as $\frac{y_{i}-l_{i}}{c(i)-l_{i}}$. The EPM $\Delta$ is defined as the optimization problem

$$
\begin{array}{lr}
\min f, & \\
\frac{y_{i}-l_{i}}{c(i)-l_{i}}-\frac{y_{j}-l_{j}}{c(j)-l_{j}} \leqslant f, & \forall(i, j) \in N \times N, \\
y(S) \leqslant c(S), & \forall S \subset N, \\
y(N)=c(N) . &
\end{array}
$$


Where $l_{i}$ is the optimal objective function value to the optimization problem

$$
\begin{aligned}
& \min y_{i}, \\
& y(S) \leqslant c(S), \\
& y(N)=c(N) .
\end{aligned} \quad \forall S \subset N,
$$

The value of $l_{i}$ can be seen as the bargaining power of player $i$ with respect to the core. The difference $c(i)-l_{i}$ is, therefore a measure between the individual cost and the bargaining power. If $y_{i}=l_{i}$ then the fraction will be zero, e.g. $0 \%$, and if $y_{i}=c(i)$ the fraction is 1 , e.g. $100 \%$. It might occur that $l_{i}=c(i)$, which would result in a zero in the denominator. This happens when $m_{i}^{c}=c(i)$ and thus occurs especially when player $i$ is a dummy player. We might decide a priori that $y_{i}=c(i)$ for dummy players. Hence the dummy player property is fulfilled by the solution concept.

Consider the game where $c(1)=-10, c(2)=100, c(\{1,2\})=0$. The EPM yields the solution $(-10,10)$, thus allocating all profit to player 2, i.e., the cost for player 2 is reduced by 90 and the cost for player 1 is reduced by 0 , even though both players have contributed equally. A more intuitive cost allocation would be $(-55,55)$, which is the solution according to the Shapley value and the Nucleolus, defined below, where both players make a profit of 45 . This is the solution according to the EPM $\Delta$. The EPM $\Delta$ may not be unique, thus lexicography can be applied to the $\operatorname{EPM} \Delta$, in the same way as for the EPM.

\section{Nucleolus}

Let the excess vector $\theta(y)$ be the non-decreasing list containing all excess values, $e(S, y)=c(S)-y(S)$.

The Nucleolus was introduced by Schmeidler (1969). The Nucleolus is defined as the outcome that satisfies individual rationality with the lexicographically largest excess vector, or mathematically $\{y \in$ $\left.X \mid \theta(y) \geqslant_{L} \theta(\widehat{y}) \forall \widehat{y} \in X\right\}$ where $X=\left\{y \in \mathbb{R} \mid y(N)=c(N), y_{i} \leqslant c(i)\right\}$.

Calculating the Nucleolus involves solving a number of optimization problems iteratively. Procedures to calculate the Nucleolus can be found in e.g. (Dragan, 1981; Kopelowitz, 1967). 
It may be noted that Schmeidler's definition uses the lexicographically smallest non-increasing excess vector, which corresponds to cooperative profit games.

From an application point of view, two positive attributes about the Nucleolus are that if the core is non-empty then the solution according to the Nucleolus is in the core. The other is that the solution is unique.

If, for a given cooperative game $(N, c)$, there is no solution that satisfies both individual rationality and efficiency, e.g. $\sum_{i \in N} c(i)<c(N)$, then there is no solution according to the Nucleolus. However, if the individual rationality constraints are removed, a solution is always found. The Nucleolus without the individual rationality constraints is called the pre-Nucleolus. If there exists a solution according to the Nucleolus, then it is the same as the solution according to the pre-Nucleolus.

\section{Shapley value}

The Shapley value (Shapley, 1953) is a combinatorial construction where the marginal cost, $m_{(i, S)}=c(S)-c(S \backslash\{i\})$, plays a major role. The grand coalition can be formed when the players are added sequentially. There are $|N|$ ! ways to form the grand coalition, starting with the empty set. For a specific player, $i$, and a specific coalition, $S$ such as $i \in S$, there are $(|S|-1)$ ! ways to form the coalition $S \backslash\{i\}$ and $(|N|-|S|)$ ! ways to form the grand coalition, from $S$. The Shapley value for a specific player, $i$, is a weighted average of the marginal costs, where the weights correspond to the number of ways the grand coalition can be formed, given that the first players to join are those in $S \backslash\{i\}$. A more compact formula is

$$
y_{i}=\sum_{S \subseteq N} \frac{(|S|-1) !(|N|-|S|) !}{|N| !} \cdot m_{(i, S)} .
$$

It should be noted that the Shapley value yields a unique solution. It is computationally easy with a given characteristic function but there is no guarantee that the Shapley value yields a solution in the core. This last attribute makes the Shapley value a poor choice for a solu- 
tion concept to a cost allocation problem where there is competition between the players. If the solution is not in the core, then there is economic incitement for some coalition(s) to not cooperate in the grand coalition.

\subsubsection{Other solution concepts}

\section{Egalitarian solution}

The Egalitarian solution (Thomson, 1983) is based on egalitarianism (Myerson, 1981). The idea is to minimize the largest allocated cost. Thus, this solution concept allocates the cost of the grand coalition, $c(N)$, equally amongst the players. The Egalitarian solution satisfies efficiency, since $y(N)=\sum_{i \in N} \frac{c(N)}{n}=n \cdot \frac{c(N)}{n}=c(N)$. However, it does not satisfy individual rationality, nor group rationality. For instance, given a game with the characteristic function $c(1)=1, c(2)=9, c(\{1,2\})=6$, the Egalitarian solution states that $y_{1}=y_{2}=3$ for this game. Clearly, player 1 pays more than $\mathrm{s} / \mathrm{he}$ would do alone. This example shows that the Egalitarian does not satisfy individual rationality, and therefore, does not satisfy group rationality either. However, it fulfills uniqueness.

$\tau$-value

The total cost for the grand coalition can be divided into two parts, a separable part (grand coalition marginal cost, $m_{i}^{c}=c(N)-c(N \backslash\{i\})$ and an non-separable part, $g(N)=c(N)-\sum_{i \in N} m_{i}^{c}$. The $\tau$-value (Tijs, 1981) is a solution concept which allocates the non-separable part amongst the players with a weight vector $\psi=\left(\psi_{1}, \psi_{2}, \ldots, \psi_{n}\right)$ and the separable part is allocated to the respective players. The allocation for player $i$ is calculated as $y_{i}=m_{i}^{c}+\frac{\psi_{i}}{\sum_{j \in N} \psi_{j}} g(N)$. Below, three special cases of the $\tau$-value are presented, each with specific values for the weight vector $\psi$. 


\section{Equal charge method}

The equal charge method (Tijs, 1981) is a solution concept that allocates for each player their respectively grand coalition marginal cost and allocates the non-separable part equally amongst the players. Thus, the equal charge method has the weight vector $\psi_{i}=1, \forall i \in N$

\section{Alternative cost avoided method}

The alternative cost avoided method (Tijs and Driessen, 1986) allocates for each player their respectively grand coalition marginal cost. The non-separable part is allocated with a weight that is, for each player, the difference between individual cost and marginal cost. The players with a higher difference are allocated a higher amount of the non-separable part. The weights used for the alternative cost avoid method are calculated as $\psi_{i}=c(i)-m_{i}^{c}, \forall i \in N$.

\section{Separable cost remaining benefits method}

The separable cost remaining benefit method (Tijs and Driessen, 1986) is a slight modification of the alternative cost avoided method. The only difference is that $\psi_{i}=\min \left(c(i), b_{i}\right)-m_{i}^{c}, \forall i \in N$ where $b_{i}$ is player $i$ 's benefit if only player $i$ 's purposes are served, assuming such benefit can be measured. Otherwise, the separable cost remaining benefit method is equivalent to the alternative cost avoided method.

\subsection{Some comments on game theory}

A poorly fitting property for solution concepts for cooperative cost games is the kick-back property. The issue is that no solution concept that satisfies efficiency can satisfy the kick-back property. At least one element in y will be negative if the cost of the grand coalition is negative. There are games where all values in the characteristic function are non-negative, and for which some solution concepts yield solutions with at least one negative value, e.g. $c(1)=1, c(2)=2$ and 
$c(\{1,2\})=0$. Both the Shapley value and the Nucleolus yield the solution $(-0.5,0.5)$ which is also a solution in the core.

However, for cooperative profit games, the kick-back property is relevant. In such a context, the implication of the kick-back property is that no player should be allocated a negative profit, i.e. have to pay. This implication is actually the individual rationality property for profit games. One conclusion is that the kick-back property is either irrelevant or is a reformulation of an existing property.

There is a correlation between Incremental cost test and group rationality worth mentioning.

\section{Claim}

If efficiency is fulfilled, then Incremental cost (and profit) test is equivalent to group rationality.

\section{Proof}

Let $\bar{S}$ denote the set $N \backslash S$, i.e. the complement of $S$. Observe that $S$ is the complement of $\bar{S}$.

$y(S)=y(N \backslash \bar{S})=y(N)-\left(\sum_{i \in \bar{S}} y_{i}\right) \leqslant c(N)-(c(N)-c(N \backslash \bar{S}))=$ $c(N \backslash \bar{S})=c(S)$.

\subsection{Applications}

Cooperative game theory has been used in the application of transportation. Examples from the literature can be found in Section 1.2, Chapter 2 as well as in Paper 1 and Paper 3. However, cooperative game theory has also been used in other applications.

Young (1985) provides an introduction to cost allocation methods and applications. The multi purpose water reservoir problem is an application where a reservoir is to be built. It may fullfil different needs, e.g. power supply, irrigation and water consumption for households. The construction cost of the reservoir depend on which purposes it will fulfil. The cost is allocated among stakeholders representing each purpose. The problem originates from The Tennessee Valley Authority Act of the 1930s (Ransmeier, 1942). This act, which was ahead of its time, it is suggested that the cost allocation should fulfill group rationality. 
Another application is the municipality cost sharing problem where municipalities share a common supply or infrastructure and the cost is allocated on the basis of the demand. In the case described (Young et al., 1982), municipalities in the Skåne region are able to share a water supply system. If there is a cooperation, the water supply system needs to be expanded with new pipelines.

The airport landing fee problem is another application in which the infrastructural cost of a runway is allocated amongst the aircraft using the runway based on the distance they need. Naturally, larger aircraft require longer runways and are thus allocated a higher cost than smaller aircraft. The problem is presented in (Littlechild and Owen, 1973; Littlechild and Thompson, 1977) while studying a case at Birmingham airport.

A fourth application is the travel expenses problem (Young, 1985). A lecturer is invited to speak in a number of cities. Each city is a player in the cooperative cost game and the charcteristic function value is the lecturer's travel expenses for being able to give the presentation in each city of the coalition. An alternative description of the problem is when a set of friends share a taxi. In this case, the characteristic function value is the cost of a taxi visiting each player in the coalition. In the lecturer case, if only ticket prices are taken into account, then the characteristic function value is the cost of the optimal solution to a Travelling Salesman Problem (TSP). For the taxi fare case, the problem type is an open TSP, i.e. it is not required to return to an initial node (home city). A similar application, common in telecommunication, is the cost allocation of a minimum cost spanning tree. A spanning tree is a set of arcs connecting all nodes in a network and the minimum cost spanning tree is the spanning tree with the least summed arc cost, i.e. $\sum_{(i, j) \in A_{s}} c_{i j}$ where $A_{s}$ is the set of arcs in the spanning tree $s$ and $c_{i j}$ is the arc cost of arc $(i, j)$. The total cost is allocated amongst the nodes, in all three cases; lecturer, taxi fare and minimum cost spanning tree.

Dror (1990) studies cost allocation in the context of the TSP, the bin-packing problem and the knapsack problem. The bin-packing problem can be seen as a situation when there are items (each with a size) which are to be placed in bins (each with a size and a price). The objective is to place all the items in bins at the lowest investment 
cost. The knapsack problem can be seen as follows. There are items (each with a size and a value) and a knapsack (with a size). The objective is to place as much value as possible in the knapsack by filling it with the items, without exceeding the size of the knapsack.

Lemaire $(1984 ; 1991)$ states several cases, existing projects, where concepts from cooperative game theory have been used, e.g. tax allocation among the divisions in a company, maintenance cost allocation for users of telephone lines and several construction projects where a number of stakeholders are involved.

Sanchez-Soriano (2013) has presented an overview of game theory applications in engineering. An application in railways arose when, due to political directives, the transportation operations and infrastructure management were separated. The infrastructure cost game (Fragnelli et al., 2000; Norde et al., 2002) was presented while the infrastructure management part of the railway case was studied. The infrastructure cost game consists of an investment part, which is basically the airport landing fee problem, and an maintenance part, the maintenance game (Fragnelli et al., 2000). The characteristic function of the infrastructure game is the sum of the characteristic functions of the infrastructure cost game and the maintenance game.

Puerto et al. (2001) present the continuous single facility location game. A set of players are investing in a new facility, which is located such that the total cost, e.g. transportation cost with respect to a cost function and installation cost, is minimized. The characteristic function is the the total cost with respect to the players in respective coalitions.

Fragnelli et al. (2004) study the bus game. Travel agencies arrange trips. Even though they might only need a strict subset of the seats of a bus, they still need to rent the whole bus. The characteristic function values are the number of buses required for the total number of passengers in each coalition. This type of game is applicable to many other problems with similar integer constraints.

Dror and Hartman (2011) have presented a survey of inventory game applications of game theory. The inventory game stems from supply chain management, where a firm has to meet the demand of their customers by ordering the goods from their suppliers. The firm has 
an inventory and the problem is to decide what quantity to order from the suppliers. By cooperating with other firms at the same level in the supply chain, the order cost, e.g. administrative work and quantity discount, may be reduced. In the survey, two problem types are presented, the joint replenishing game (Meca et al., 2004) and the newsvendor centralization game (Slikker et al., 2005). In the latter game, the goods ordered have an expiring date, e.g. newspapers and fresh food. 


\section{Chapter 4}

\section{Summary of Papers}

In the following chapter, Paper 1-3 are summarized. The methods presented in Paper 1 and Paper 3 have been tested on two cases of cooperation in transportation planning applications. The cases and applications are described in Section 4.1 and the main results and conclusions of Paper 1-3 are presented in Section 4.2.

\subsection{Case studies}

In Paper 1, a cooperation in a CL context is considered, see Section 4.1.1. As a representative of different external stakeholders, e.g. inhabitants, tourists and estate owners, the municipality takes the role as the initiator and enabler of a cooperation between freight forwarders with goods bound for the urban area. The goods are consolidated at a CDC located near the city entrance/exit.

In Paper 3, a cooperation between forest companies is considered, see Section 4.1.2. These companies cooperate in terms of the supply and transportation of a common resource, wood. It is assumed that one of the forest companies, the initiator, invites the other forest companies to participate in the cooperation. However, who will join or in what order the forest companies will do so is not predetermined. 
The common theme of the two cases is a cooperation in transportation planning with a stakeholder initiating the cooperation. In the first case, it is assumed that either all or no stakeholders will cooperate, while in the second case, it is possible for any subset of the stakeholders to cooperate.

\subsubsection{City logistics}

Even though logistics and supply chain management of freight transportation has been thoroughly studied, the field of CL did not appear until the late 1990s. Taniguchi et al. (1999) and Taniguchi et al. (2001, p.13) define CL as 'the process for totally optimizing the logistics and transport activities by private companies in urban areas while considering the traffic environment, the traffic congestion and energy consumption within the framework of a market economy'.

A detailed report by Allen et al. (2007), describes CL and can be summarized as follows: There are several types of stakeholders, both external and internal, who are affected by CL (e.g. transportation companies, goods receivers/owners, real estate owners, visitors, inhabitants and the municipality); they have diverse objectives and they value different impacts differently. The impacts include economical (travel time, resource usage), environmental (pollutant emissions) and social (risk for injuries, public health, quality of life) impacts. There are several CL measures, but due to the stakeholders diverse objectives, the measures are often positive for some stakeholders and negative for others. The measures range from infrastructural and policy based measures to logistical and technological measures.

Characteristics of an urban area make the transportation planning in this context different from that of a regional or international context. Aspects which are exclusive to the urban area must be taken into account. In the urban area, the streets are more narrow, the traffic is more dense and non-occupied parking spaces are sparse. The delivery points are geographically closer to each other and the number of stops is larger. This results in more frequent parking, the ratio between the time spent handling goods while parked and the time spent driving is much larger for urban areas than for long distance deliveries. There are external stakeholders affected by the goods transportation in the 
urban area, e.g. inhabitants. In order to maintain a high quality of life and a sustainable city, environmental friendly vehicles are preferable. Schliwa et al. (2015) investigate the potential use of cargo cycles in the UK and Browne et al. (2011) evaluate the use of electric vehicles in central London.

In $\mathrm{CL}$, it is common to include a CDC as one mean to reduce the number of large trucks in urban areas and to make goods distribution more efficient, e.g. (Ambrosino et al., 2007). One possible location for a CDC is on the outskirts of the urban area, somewhere that is easily accessed from the main road, while not too far from the urban area. If the CDC is located in the middle of the urban area, the large trucks with goods the CDC, need to travel into the urban area, and the number of large trucks in the urban area is not reduced. Goods bound for customers in the urban area are redistributed at the CDC and transited to other routes and vehicles for an efficient urban distribution.

The fictitious case considered in Paper 1 consists of a number of freight forwarders operating in an urban area. There are delivery points spread out throughout the urban area, and each delivery point corresponds to a customer. Some customers receive deliveries from multiple freight forwarders. Prior to the cooperation, the freight forwarders operate individually with no coordination. The municipality is interested in reducing the traffic impact of the freight forwarders by making their operations more efficient. The municipality suggests that the freight forwarders cooperate and use a CDC. Two scenarios for the case are considered. They differ by a small change in demand for one customer, resulting in a change in the characteristic function values.

The transportation problem, i.e. delivery of the goods, for each coalition, is solved by minimizing the transportation cost of a corresponding VRP to optimality, as if the coalition acted without the others. According to Cherrett et al.(2009), in reality, each vehicle may have about 50 delivery points. Due to the computational time, solving such a big VRP to optimality is not reasonable. The case considered in the paper is smaller. 


\subsubsection{Forest industry}

The forest industry produces wood based products, e.g. paper, pulp, carton, wood planks and bio fuel. The activities of the forest industry include forest management, harvesting, transportation, production and sales. D'Amours et al. (2008) present a descriptive model of the wood fiber flow in the supply chain, from forest to customer, for different forest industry products.

Forest management, or silviculture, consist of activities such as planting, tending, fertilization and thinning. Thompson et al. (2003) present a review of papers studying the long term effects on vertebrate wildlife by intensive silviciulture and Brais et al. (2015) study the effects wood ash fertilization has on spruce and pine growth. Forest management requires strategic planning. The planning horizon is long due to the life cycles of the trees planted, i.e. time from plant to fully grown tree. The trees will meet future demands, and different forest industry products require different types of wood.

Harvesting is planned on a tactical level. Decisions about 'Which areas to harvest and where to build forest roads for easier access?' are made. The wood is cut into either logs or chips, depending on the production intended. The harvested wood is transported by trucks, either directly to industries or to railway hubs or seaports for further transport. Andalaft et al. (2003) have developed a mixed integer optimization model, which integrates harvesting, forest road building and material flows.

The case considered in Paper 3 consists of some forest companies operating in the southern part of Sweden. Each has harvesting areas and industries. The part of their operations which is subject to a potential cooperation is the transportation between the harvest areas and the industries, i.e. the transportation problem. A cooperation may reduce the total transportation cost due to synergy effects when the wood is bartered. In Paper 3, the companies join the cooperation sequentially, starting with the dominant player, the initiator. The other companies are invited to join the cooperation. Upon announcing the supplies and demands of the company, the company will receive a preliminary allocated cost, based on the current cooperation. The preliminary allocated cost is an upper bound, i.e. the final allocated 
cost will not exceed the preliminary cost. The company then decides whether or not to join the cooperation. The system optimal solution will be achieved if all companies accept to join the cooperation.

The transportation problem is a network flow problem, solved using FlowOpt by Forsberg et al. (2005). The data, provided by the companies, is from all the operations performed by the companies during the period of one month. The cost reductions are made because of synergies with the locations of supply nodes and demand nodes, i.e. the wood is bartered when there is a transport from the supply node of company $i$ to the demand node of company $j$. The calculated costs used in Paper 3 are given a priori, and are the same as those of Frisk et al. (2010).

\subsection{Results and summary of Paper 1-3}

In Paper 1 and Paper 3, the concept collaboration is used. In this context it is interchangeable with the concept cooperation used in this thesis.

\subsubsection{Summary of Paper 1}

In Paper 1, the municipality is a dominant player, an enabler of the cooperation in the cost allocation problem. The municipality itself has no operational cost, which is abnormal for a stakeholder in transportation planning. It is not possible to use the EPM since the individual cost for the municipality (numbered 0 in the paper) is zero, i.e. $c(0)=0$ implies a zero in the denominator. In Paper 1 , the relative cost of the municipality is instead defined as for the EPM $\Delta$, i.e. $\frac{y_{0}-l_{0}}{c(0)-l_{0}}$. In order to maintain the cooperation, i.e. yield stable cost allocations, it is suggested that the municipality uses side payments. This is done by using the v-core and letting the municipality pay the additional cost $v$. Cost allocations according to the EPM (with the redefined relative cost for the municipality), the Shapley value and the Nucleolus, are compared and discussed from a cooperative cost game point of view. In one of the scenarios, the cost allocation according to the Shapley value is not stable. In another scenario, when 
the municipality uses side payments and the Nucleolus is considered, the municipality is allocated a negative cost, and ends up with a positive net profit, even though the municipality bears some extra costs $(v \geqslant 0)$ in order to ensure a stable cooperation.

\subsubsection{Summary of Paper 2}

Paper 2 is a note, a short article, in which the EPM is discussed. In some cases, the EPM yields any of infinity many cost allocation candidates. From an application point of view, this is troublesome. This means that a player's allocated cost depends on arbitrary factors, e.g. a player may be allocated a higher cost for being number 5 than for being number 4 . In order to tackle this issue, an extension of the the EPM is presented, i.e. the EPML. The EPML reduces the number of cost allocation candidates to one, a unique cost allocation. This is done by identifying which players' allocated cost is not unique and then the difference in relative savings between those players are minimized further. Each time the difference in relative savings is minimized, at least two players' allocated costs are unique. A unique solution is therefore found in a finite number of steps (identification + reoptimization). The fundamental idea of the EPM is respected and preserved by the extension. Some numerical examples are presented as to illustrate the differences between the EPM and the EPML.

\subsubsection{Summary of Paper 3}

In Paper 3, cooperation where stakeholders join sequentially are studied. A sequence of stakeholders can be seen as a path in a network, starting with a single stakeholder, and the size of the cooperation increases until the end, where all stakeholders (eventually) cooperate.

A Monotonic Path (MP) is a path in the network mentioned above, such that no stakeholder disbenefits when a new stakeholder joins, i.e. no stakeholder has economical incitement to leave the cooperation. The path will lead to a full cooperation. The number of MPs are calculated by going through all possible paths in the network. Similar work has been done by Cruijssen et al. (2005) where groups 
of shippers with high synergies can be proactively selected by a LSP, i.e. the LSP chooses a specific path in the network. However, unlike Cruijssen et al., here all paths are considered and thus no stakeholder is proactively selected.

Cruijssen et al. (2005) only consider the Shapley value whereas a number of mechanisms to allocate the costs are tested in Paper 3. Two of the mechanisms ensure that all paths are MPs, i.e no matter in what order the stakeholders join, the path is a MP. 



\section{Chapter 5}

\section{Conclusions and Future Research}

In Paper 1 and Paper 3, cooperative game theory is used as an academic tool to study cooperation in different transportation planning cases: the consolidation of urban freight; and cooperative forest transportation planning. In the literature, stakeholders are commonly treated equally. However, in reality, it can be argued that in some cases, the stakeholders should not be treated equally. This is exemplified in Paper 1 and Paper 3, where a dominant player is included. The dominant player is the initiator and enabler of the cooperation. In Paper 2, a solution concept from cooperative game theory has been further developed.

\subsection{Conclusions and potential continuation of Paper 1-3}

In Paper 1, it is shown that a stable cooperation can be achieved if one of the stakeholders, in this case the municipality, is willing to use side payments. In this case, the municipality covers some of the costs of the cooperation before any allocation of costs is made, thus, pro- 
viding economic incitement by potentially reducing the allocated cost for the other stakeholders. The numerical examples are of limited size and therefore the results are not necessarily representative for a realistic scenario. A natural continuation would be to include a more realistic scenario and perhaps also real life data. The VRPs solved in Paper 1, account for vehicle capacity and customer's demand, and the transportation cost is minimized. Possible extensions to this model are e.g. time window constraints, the use of a heterogeneous fleet and dynamic travel times. Other objectives which stem from the stakeholders' different objectives could be incorporated. These might include non-monetary costs, e.g. emissions and customer satisfaction.

In Paper 2, the EPML, an extended version of the EPM, is presented. The extension guarantees a unique solution to any cost allocation game with a non-empty core, which is not always the case with the EPM. Two such cases are provided in Paper 2. The EPML is used in Paper 3.

In Paper 3, a cooperation is preceded by a simultaneous invitation to the stakeholders, in this case forest companies, and each stakeholder either accepts or declines a preliminary cost allocation upon announcing its transportation needs, e.g. supplies, demands and locations. The announcements occur sequentially. It is not possible to predetermine who will accept and in which order the stakeholders will join. In Paper 3, it is shown that a stable cooperation can be achieved using the cost allocation mechanisms suggested. The probability of achieving a stable cooperation is shown to be dependent on the cost allocation mechanism used. Two of the (fourteen) suggested cost allocation mechanisms guarantee a stable cooperation, regardless of the order in which the stakeholders join. A proof that this holds for a general case is given in Paper 3, assuming that the cooperative game is 'proper'. In this context, 'proper' means that, from a system optimal perspective, it is never disadvantageous to form a larger cooperation. This is defined mathematically in Chapter 3 and Paper 3. The results are based on a specific case from the literature, (Frisk et al., 2010), and thus, the extent to which the results are case sensitive is uncertain. However, there are no case-specific assumptions. It is therefore plausible that the results can be generalised. A natural continuation of Paper 3 would be to apply the ideas to other cases 
and transportation planning applications.

\subsection{Future research and discussion}

If real life data are to be used, new difficulties arise. In Sweden, the only public data on freight is aggregated on a regional level and is not suitable for operational level models. The lack of public freight data, especially for urban areas, is pointed out in e.g. (Björklund and Gustafsson, 2015). The transportation companies do have useful data, but are not very keen on sharing it. If a cooperation is modeled realistically, data from different operators is needed. The likelihood of data sharing is reduced due to the competition aspects.

When the problem size increases to realistic proportions, and if the problem is modeled as a VRP, it is no longer reasonable to find a global optimal solution as the computational time is too long. Instead, the problem needs to be solved using heuristic methods. A heuristic method is a solving algorithm which finds feasible (hopefully good) solutions in a reasonable time. But there is generally no guarantee that the best found solution is a global optimal solution. A possible continuation of the author's research would be to develop heuristic methods for solving VRPs, that are computationally suitable for cost allocation applications.

If the characteristic function values are defined by heuristic solutions, then it is uncertain how well the values correspond to the actual cost of a cooperation between the players in each coalition. It is also difficult to determine whether or not a cost allocation is fair when comparing it with values that do not have any certainty of how well these correspond to the optimal costs. How this uncertainty affects the cost allocation game is a future research area.

From a cooperative game theory point of view, it would seem that cooperation is an obvious choice for transportation companies to improve their operations. So why is there not more cooperations in transportation planning? This question borders the scientific fields of behaviour science, economics and business psychology. One explanation could be a lack of trust, both towards the competitors and the cooperation itself. Perhaps the companies argue that they are already 
efficient, have already achieved optimal operations and that involving more stakeholders only complicates things. According to Ballou et al. (2000), trust amongst stakeholders in a cooperation is built on being able to uniformally define and measure costs, share information and agree on how costs and benefits should be allocated. Ballou et al. (2000) speculate that stakeholders fear that competitors will use shared information to their advantage. The purpose of this thesis is not to persuade and convince, but to provide the decision makers with input to help this process. This is done by showing the potential of cooperation and by suggesting how costs could be allocated in different applications. 


\section{Bibliography}

Agarwal, R. and Ergun, O. (2010). "Network Design and Allocation Mechanisms for Carrier Alliances in Liner Shipping". In: Operations Research 58.6, pp. 1726-1742.

Allen, J., Thorne, G., and Browne, M. (2007). BESTUFS Good practice guide on urban freight transport. Tech. rep. BESTUFS.

Ambrosino, G., Boero, M, Di Bugno, M, Guerra, S, and Librato, A (2007). "A centre for eco friendly city freight distribution: Urban logistics innovation in a mid-size historical city in Italy". In: $I C L$ $200 \%$.

Andalaft, N., Andalaft, P., Guignard, M., Magendzo, A., Wainer, A., and Weintraub, A. (2003). "A Problem of Forest Harvesting and Road Building Solved through Model Strengthening and Lagrangean Relaxation". English. In: Operations Research 51.4, pp. $613-628$.

Bailey, E., Unnikrishnan, A., and Lin, D.-Y. (2011). "Models for minimizing backhaul costs through freight collaboration". In: Transportation Research Record: Journal of the Transportation Research Board 2224, pp. 51-60.

Ballou, R. H., Gilbert, S. M., and Mukherjee, A. (2000). "New Managerial Challenges from Supply Chain Opportunities". In: Industrial Marketing Management 29.1, pp. 7-18.

Bengtsson, M. and Kock, S. (2000). "Coopetition in Business Networksto Cooperate and Compete Simultaneously". In: Industrial Marketing Management 29.5, pp. 411-426. 
Björklund, M. and Gustafsson, S. (2015). "Toward sustainability with the coordinated freight distribution ofmunicipal goods". In: Journal of Cleaner Production 98.0, pp. 194-204.

Brais, S., Belanger, N., and Guillemette, T. (2015). "Wood ash and $\mathrm{N}$ fertilization in the Canadian boreal forest: Soil properties and response of jack pine and black spruce". In: Forest Ecology and Management 348.0, pp. 1-14.

Browne, M., Woodburn, A., and Allen, J. (2007). "Evaluating the potential for urban consolidation centres". In: European Transport 35 , pp. $46-63$.

Browne, M., Allen, J., and Leonardi, J. (2011). "Evaluating the use of an urban consolidation centre and electric vehicles in central London". In: \{IATSS\} Research 35.1, pp. 1-6.

Cherrett, T., McLeod, F., Maynard, S., Hickford, A., and Allen, J. (2009). "Understanding retail supply chains to enable greenerlogistics-A case study of 'delivery' and 'take-back' mechanisms in Winchester". In: Proceedings of the 14th Annual Logistics Research Network Conference 9-11 September, Cardiff, pp. 80-87.

Crainic, T. G., Ricciardi, N., and Storchi, G. (2009). "Models for Evaluating and Planning City Logistics Systems". In: Transportation Science 43.4, pp. 432-454.

Cruijssen, F., Borm, P., Fleuren, H., and Hamers, H. (2005). "Insinking: a methodology to exploit synergy in transportation". CentER Discussion Paper 2005-121. Tilburg University.

D'Amours, S., Rönnqvist, M., and Weintraub, A. (2008). "Using operational research for supply chain planning in the forest products industry". In: INFOR: Information Systems and Operational Research 46.4, pp. 265-281.

Dragan, I. (1981). "A procedure for finding the nucleolus of a cooperativen person game". English. In: Zeitschrift für Operations Research 25.5, pp. 119-131.

Dror, M and Hartman, B. (2011). "Survey of cooperative inventory games and extensions". English. In: The Journal of the Operational Research Society 62.4, pp. 565-580. 
Dror, M. (1990). "Cost allocation: the traveling salesman, binpacking, and the knapsack". In: Applied Mathematics and Computation 35.2, pp. 191-207.

Duin, J. van, Tavasszy, L., and Quak, H. (2013). "Towards E(lectric)urban freight: first promising steps in the electric vehicle revolution". In: European Transport Trasporti Europei 54.54, no 9.

Engevall, S., Göthe-Lundgren, M., and Värbrand, P. (2004). "The Heterogeneous Vehicle-Routing Game". In: Transportation Science 38.1 , pp. $71-85$.

Eriksson, J., Karlsson, R., Fors, T., Fredholm, O., Lång, A.-M., and Svensson, T. (2006). SAMLIC - Pilotförsöket. Tech. rep. The Swedish National Road and Transport Research Institute (VTI).

Forsberg, M, Frisk, M, and Rönnqvist, M (2005). "FlowOpt-A decision support tool for strategic and tactical transportation planning in forestry". In: International Journal of Forest Engineering 16.2, pp. 101-114.

Fragnelli, V., García-Jurado, I., Norde, H., Patrone, F., and Tijs, S. (2000). "How to Share Railways Infrastructure Costs?" In: Game practice: contributions from applied game theory. Springer, pp. 91101.

Fragnelli, V., Garcia-Jurado, I., and Mez-Naya, L. (2004). "A note on bus games". In: Economics Letters 82.1, pp. 99-106.

Frisk, M., Göthe-Lundgren, M., Jörnsten, K., and Rönnqvist, M. (2010). "Cost allocation in collaborative forest transportation". In: European Journal of Operational Research 205.2, pp. 448-458.

Gillies, D. B. (1959). "Contributions to the Theory of Games Volume IV". In: Princeton University Press. Chap. Solutions to general non-zero-sum games, pp. 47-85.

Göthe-Lundgren, M., Jörnsten, K., and Värbrand, P. (1996). "On the nucleolus of the basic vehicle routing game". In: Mathematical programming 72.1 , pp. 83-100.

Guajardo, M. and Rönnqvist, M. (2015). "Operations research models for coalition structure in collaborative logistics". In: European Journal of Operational Research 240.1, pp. 147-159. 
Kopelowitz, A (1967). Computation of the Kernels of Simple Games and the Nucleolus of N-person Games. Ed. by T. H. U. o. J. Research Memorandum No. 31 Department of Mathematics. Defense Technical Information Center.

Lemaire, J. (1984). "An Application of Game Theory: Cost Allocation". In: ASTIN Bulletin 14 (01), pp. 61-81.

Lemaire, J. (1991). "Cooperative Game Theory and its Insurance Applications". In: ASTIN Bulletin 21 (01), pp. 17-40.

Li, S., Yu, Z., and Dong, M. (2015). "Construct the stable vendor managed inventory partnership through a profit-sharing approach". In: International Journal of Systems Science 46.2, pp. 271-283.

Littlechild, S. C. and Owen, G. (1973). "A Simple Expression for the Shapely Value in a Special Case". English. In: Management Science 20.3, pp. 370-372.

Littlechild, S. C. and Thompson, G. F. (1977). "Aircraft Landing Fees: A Game Theory Approach". English. In: The Bell Journal of Economics 8.1, pp. 186-204.

Meca, A., Timmer, J., Garcia-Jurado, I., and Borm, P. (2004). "Inventory games". In: European Journal of Operational Research 156.1, pp. $127-139$.

Moen, O. (2014). "Co-distribution of Municipal Goods in Sweden Procurement from a New Standpoint". In: Procedia - Social and Behavioral Sciences 125. Eighth International Conference on City Logistics 17-19 June 2013, Bali, Indonesia, pp. 484-495.

Myerson, R. B. (1981). "Utilitarianism, Egalitarianism, and the Timing Effect in Social Choice Problems". English. In: Econometrica 49.4, pp. 883-897.

Neumann, J. v. and Morgenstern, O. (1944). Theory of games and economic behavior. Princeton university press.

Norde, H., Fragnelli, V., Garcia-Jurado, I., Patrone, F., and Tijs, S. (2002). "Balancedness of infrastructure cost games". In: European Journal of Operational Research 136.3, pp. 635-654. 
Östlund, J. and Myhr, A. (2015). Transportarbete 1950-2014 (Swedish). Online, Trafikanalys.

Özener, O. and Ergun, O. (2008). "Allocating Costs in a Collaborative Transportation Procurement Network". In: Transportation Science 42.2, pp. 146-165.

Puerto, J., Garcia-Jurado, I., and Fernandez, F. R. (2001). "On the core of a class of location games". English. In: Mathematical Methods of Operations Research 54.3, pp. 373-385.

Ransmeier, J. S. (1942). The Tennessee Valley Authority: a case study in the economics of multiple purpose stream planning. Vanderbilt University Press Nashville, TN.

Ropke, S. and Pisinger, D. (2006). "A unified heuristic for a large class of Vehicle Routing Problems with Backhauls". In: European Journal of Operational Research 171.3. Feature Cluster: Heuristic and Stochastic Methods in Optimization Feature Cluster: New Opportunities for Operations Research, pp. 750-775.

Sanchez-Soriano, J. (2013). "An overview on game theory applications to engineering". In: International Game Theory Review 15.03. art. no. 1340019 .

Schliwa, G., Armitage, R., Aziz, S., Evans, J., and Rhoades, J. (2015). "Sustainable city logistics Making cargo cycles viable for urban freight transport". In: Research in Transportation Business \&6 Management 15.0. Managing the Business of Cycling, pp. 5057.

Schmeidler, D. (1969). "The Nucleolus of a Characteristic Function Game". In: SIAM Journal on Applied Mathematics 17.6, pp. 11631170.

Shapley, L. S. (1953). "A value for n-person games". In: Contributions to the theory of games II. Princeton University Press, Princeton.

Shapley, L. S. and Shubik, M. (1963). The Core of an Economy with Nonconvex Preferences. Memorandum (Rand Corporation). Rand Corporation.

Shapley, L. S. and Shubik, M. (1966). "Quasi-Cores in a Monetary Economy with Nonconvex Preferences". English. In: Econometrica 34.4, pp. 805-827. 
Slikker, M., Fransoo, J., and Wouters, M. (2005). "Cooperation between multiple news-vendors with transshipments". In: European Journal of Operational Research 167.2, pp. 370-380.

Stadtler, H. and Kilger, C. (2005). Supply Chain Management and Advanced Planning: Concepts, Models, Software And Case Studies. Springer.

Taniguchi, E., Thompson, R. G., and Yamada, T. (1999). "Modelling City logistics." In: City logistics I. City logistics I. Institute of Systems Science Research, pp. 3-37.

Taniguchi, E., G.Thompson, R., Yamada, T., and Duin, R. van (2001). City Logistics: Network Modelling and Intelligent Transport Systems. Pergamon.

Taniguchi, E. (2014). "Concepts of City Logistics for Sustainable and Liveable Cities". In: Procedia - Social and Behavioral Sciences 151.0. Green Cities - Green Logistics for Greener Cities, Szczecin, 19-21 May 2014, pp. 310-317.

Tavasszy, L., Thissen, M., and Ruijgrok, C. (2003). "Emerging global logistics networks: implications for transport systems and policies". In: Growth and Change 34.4, pp. 456-472.

Teo, J. S., Taniguchi, E., and Qureshi, A. G. (2012). "Evaluating City Logistics Measure in E-Commerce with Multiagent Systems". In: Procedia - Social and Behavioral Sciences 39.0. Seventh International Conference on City Logistics which was held on June 79,2011, Mallorca, Spain, pp. 349-359.

Thompson, I. D., Baker, J. A., and Ter-Mikaelian, M. (2003). "A review of the long-term effects of post-harvest silviculture on vertebrate wildlife, and predictive models, with an emphasis on boreal forests in Ontario, Canada". In: Forest Ecology and Management 177.13, pp. 441-469.

Thomson, W. (1983). "Problems of fair division and the Egalitarian solution". In: Journal of Economic Theory 31.2, pp. 211-226.

Tijs, S. (1981). "Game Theory and Mathematical Economics". In: North-Holland Publisher. Chap. Bounds for the Core and the tauValue, pp. 123-132. 
Tijs, S. and Driessen, T. (1986). Game theory and cost allocation problems. Open Access publications from Tilburg University urn:nbn:nl:ui:12-154261. Tilburg University.

Toth, P. and Vigo, D. (2002). The Vehicle Routing Problem. Monographs on Discrete Mathematics and Applications. Society for Industrial and Applied Mathematics.

Tragantalerngsak, S., Holt, J., and Rönnqvist, M. (2000). "An exact method for the two-echelon, single-source, capacitated facility location problem". In: European Journal of Operational Research 123.3, pp. 473-489.

Tucker, A. W. (1983). "The Mathematics of Tucker: A Sampler". English. In: The Two-Year College Mathematics Journal 14.3, pp. 228-232.

Tucker, A. W. (1950). "A two-person dilemma". In: Readings in games and information, pp. 7-8.

Vanovermeire, C. and Sörensen, K. (2014). "Measuring and rewarding flexibility in collaborative distribution, including two-partner coalitions". In: European Journal of Operational Research 239.1, pp. 157-165.

Wangapisit, O., Taniguchi, E., Teo, J. S., and Qureshi, A. G. (2014). "Multi-agent Systems Modelling for Evaluating Joint Delivery Systems". In: Procedia - Social and Behavioral Sciences 125.0, pp. $472-483$.

Yang, D. and Odani, M. (2007). "An analysis on city freight cooperative transportation system using game theory." In: Journal of the Eastern Asia Society for Transportation Studies 7, pp. 989-1001.

Young, H. P., Okada, N., and Hashimoto, T. (1982). "Cost allocation in water resources development". In: Water Resources Research 18.3, pp. 463-475.

Young, H. P. (1985). Cost allocation : methods, principles, applications / edited by H. Peyton Young. English. North-Holland ; Sole distributors for the U.S.A. and Canada, Elsevier Science Pub. Co Amsterdam ; New York : New York, N.Y. 



\section{Abbreviations}

CDC City Distribution Center

CL City Logistics

EPM Equal Profit Method

EPM $\Delta$ Delta-EPM

EPML Lexicographic EPM

LSP Logistics Service Provider

MP Monotonic Path

TSP Travelling Salesman Problem

VMI Vendor Managed Inventory

VRP Vehicle Routing Problem 



\section{Papers}

The articles associated with this thesis have been removed for copyright reasons. For more details about these see:

http://urn.kb.se/resolve?urn=urn:nbn:se:liu:diva-121559 